OPEN ACCESS

Edited by:

Sonja Vermeren,

University of Edinburgh,

United Kingdom

Reviewed by:

Jonathan S. Reichner

Rhode Island Hospital, United States Ioannis Kourtzelis,

University of York, United Kingdom Scott I. Simon,

University of California, Davis,

United States

*Correspondence: János G. Filep

janos.g.filep@umontreal.ca

Specialty section:

This article was submitted to Molecular Innate Immunity,

a section of the journal

Frontiers in Immunology

Received: 29 January 2021 Accepted: 08 March 2021 Published: 30 March 2021

Citation:

Sekheri M, Othman A and Filep JG

(2021) $\beta 2$ Integrin Regulation of Neutrophil Functional Plasticity and Fate in the Resolution of Inflammation.

Front. Immunol. 12:660760.

doi: 10.3389/fimmu.2021.660760

\section{$\beta 2$ Integrin Regulation of Neutrophil Functional Plasticity and Fate in the Resolution of Inflammation}

\author{
Meriem Sekheri ${ }^{1,2,3}$, Amira Othman ${ }^{1,2,3}$ and János G. Filep ${ }^{1,3 *}$ \\ ${ }^{1}$ Department of Pathology and Cell Biology, University of Montreal, Montreal, QC, Canada, ${ }^{2}$ Department of Biomedical \\ Sciences, University of Montreal, Montreal, QC, Canada, ${ }^{3}$ Research Center, Maisonneuve-Rosemont Hospital, Montreal, \\ QC, Canada
}

Neutrophils act as the first line of cellular defense against invading pathogens or tissue injury. Their rapid recruitment into inflamed tissues is critical for the elimination of invading microorganisms and tissue repair, but is also capable of inflicting damage to neighboring tissues. The $\beta_{2}$ integrins and Mac-1 (CD11b/CD18, $\alpha_{M} \beta_{2}$ or complement receptor 3 ) in particular, are best known for mediating neutrophil adhesion and transmigration across the endothelium and phagocytosis of microbes. However, Mac-1 has a broad ligand recognition property that contributes to the functional versatility of the neutrophil population far beyond their antimicrobial function. Accumulating evidence over the past decade has demonstrated roles for Mac-1 ligands in regulating reverse neutrophil transmigration, lifespan, phagocytosis-induced cell death, release of neutrophil extracellular traps and efferocytosis, hence extending the traditional $\beta_{2}$ integrin repertoire in shaping innate and adaptive immune responses. Understanding the functions of $\beta_{2}$ integrins may partly explain neutrophil heterogeneity and may be instrumental to develop novel therapies specifically targeting Mac-1-mediated proresolution actions without compromising immunity. Thus, this review details novel insights on outside-in signaling through $\beta_{2}$ integrins and neutrophil functional heterogeneity pertinent to the resolution of inflammation.

Keywords: neutrophils, neutrophil trafficking, phagocytosis-induced cell death, apoptosis, NET formation, immunity, resolution of inflammation, Mac-1 ( $\alpha \mathrm{M} \beta 2)$

\section{INTRODUCTION}

Neutrophils are the first line of cellular defense against invading pathogens or tissue injury. Rapid recruitment of neutrophils into infected or injured tissues is critical for the elimination of invading microorganisms and tissue repair (1). Ideally, once the pathogens are cleared, cessation of neutrophil recruitment and removal of emigrated neutrophils from the inflamed site will assure timely resolution of inflammation and return to homeostasis (2-4). Aberrant neutrophil

\footnotetext{
Abbreviations: AG, azurophilic granule; C5aR, complement 5a receptor; CG, cathepsin G; EC, endothelial cell; JAM-C, junctional adhesion molecule-C; M $\Phi$, macrophage; MPO, myeloperoxidase; NE, neutrophil elastase; NET, neutrophil extracellular traps; PICD, phagocytosis-induced cell death; PR3, proteinase 3; TEM, transendothelial migration.
} 
accumulation or removal from the inflamed area inflicts damage to the surrounding tissue (2). Indeed, neutrophil-driven tissue injury has been recognized as a common mechanism underlying a wide variety of pathologies, including atherosclerosis, respiratory, autoimmune and neurodegenerative diseases, arthritis, sepsis and cancer $(5,6)$. Since neutrophils are also involved in the resolution of inflammation $(7,8)$, the balance between their protective and deleterious actions will likely determine the outcome of the inflammatory response.

The $\beta_{2}$ integrins LFA-1 (leukocyte function antigen 1, CD11a/ CD18) and Mac-1 (CD11b/CD18, $\alpha_{M} \beta_{2}$ or complement receptor 3 ) are best known for mediating neutrophil adhesion and transmigration across the activated endothelium and phagocytosis of microbes (9-11). Historically, LFA-1 and Mac1 have been considered pro-inflammatory for reduced expression or function of $\beta_{2}$ integrins causes rare immunodeficiency syndromes, leukocyte adhesion deficiency syndromes (LAD types I-III), characterized by recurrent infections $(12,13)$. The binding of Mac-1 and LFA-1 to their endothelial counter-ligand ICAM-1 or matrix components generates survival cues for neutrophils $(14,15)$. Mac-1 may also contribute to sustained inflammation by enhancing the function of heterologous receptors such as Toll-like receptors and $\mathrm{Fc} \gamma$ receptors through modulating intracellular signaling (16, 17). Accumulating data indicates that Mac-1 can bind a variety of ligands (18). This broad ligand recognition property contributes to the functional versatility of the neutrophil population and shapes innate and adaptive immune responses far beyond their antimicrobial functions. In this review, we will focus on recent advances on outside-in signaling through $\beta_{2}$ integrins and neutrophil functional heterogeneity during homeostasis and diseases. We also examine how targeting $\beta_{2}$ integrin signaling could be exploited for facilitating the resolution of inflammation.

\section{BETA 2 INTEGRIN ACTIVATION AND LIGAND BINDING}

The $\beta_{2}$ integrins, composed of a common $\beta_{2}$ (CD18) subunit complexed with unique $\alpha$ subunits (CD11a-d), are a family of myeloid cell-specific adhesion molecules with LFA-1 (leukocyte function antigen 1, CD11a/CD18) and Mac-1 (CD11b/CD18, $\alpha_{M} \beta_{2}$ or complement receptor 3) being the most studied members. $\beta_{2}$ integrin ligand binding relies on conformational changes in their ectodomain $(19,20)$. Ligation of G-proteincoupled receptors or heterologous receptors generates intracellular signals that shift the resting bent/closed $\beta_{2}$ integrin conformation (low affinity for ligands) to an extended $(\mathrm{E}+)$ and then a high-affinity conformation with an "open" headpiece $(\mathrm{H}+)$ (canonical "switchblade" model) $(19,21)$. Spatiotemporal integrin activation is governed by inside-out (i.e. activation of ligand binding function of integrins) and outside-in signaling cascades (i.e. cellular responses evoked by ligand binding to integrins) and involves inhibitory proteins and activator complexes, such as talin, kindlins, cytohesin-1 and integrin-linked kinase, interacting with the cytoplasmic tail of the $\beta$ subunit $(13,22,23)$. The Src kinase-associated phosphoprotein 2 (Skap2), which regulates actin polymerization and binding of talin-1 and kindlin-3 to the $\beta_{2}$ integrin cytoplasmic domain, is indispensable for $\beta_{2}$ integrin activation (24). Loss of Skap2 function causes a LAD-like phenotype in mice (24). Mac-1 has two spatially distinct binding sites, the $\alpha I$-domain and the lectin-like domain (25). The $\alpha$ MI-domain recognizes sequence patterns (consisting of a core of basic residues flanked by hydrophobic residues), rather than specific amino-acid sequence(s) (18) with over 30 structurally unrelated ligands, including ICAM-1, fibrinogen, complement $3 \mathrm{~b}(\mathrm{iC} 3 \mathrm{~b})$, various granule proteins and heparane sulfate (25). The interaction between the $\alpha \mathrm{MI}$-domain and cationic proteins is mediated mostly by hydrophobic contacts independently of divalent cations (26). The lectin-like domain binds $\beta$-glucans present in the fungal cell wall $(27,28)$. Table 1 lists selected Mac-1 ligands and their main biological actions.

\section{LIMITING NEUTROPHIL TRAFFICKING INTO TISSUES}

Neutrophils exit the circulation at the sites of inflammation through the classical adhesion cascade (10). The molecular mechanisms mediating and governing this multistep process as well as organ-specific differences have been described in detail $(10,29,30,65)$. In general, $\beta_{2}$ integrins play vital roles in neutrophil arrest on the activated endothelium under flow (10), transmigration through endothelial cells (66), chemotaxis (67) and neutrophil swarming (68). Counter-ligand-specific binding forces of LFA-1 and Mac-1 imply diverse roles for $\beta 2$ integrins in neutrophil recruitment (69) and determine the direction of neutrophil migration along the activated endothelium (70). Fully activated $\mathrm{E}^{+} \mathrm{H}^{+} \beta_{2}$ integrins bind ICAM-1 expressed on the opposing cells in trans and arrest neutrophil rolling (31). Studies with human neutrophils in microfluidic chambers identified high-affinity, bent conformation $\left(\mathrm{E}^{-} \mathrm{H}^{+}\right) \beta_{2}$ integrins, which face each other to form oriented nanoclusters (32) and bind ICAM-1 in cis to inhibit neutrophil rolling and consequently neutrophil adhesion to the endothelium (31). Activated $\beta_{2}$ integrins may also restrict neutrophil recruitment during acute bacterial infections, for pharmacological inhibition of high-affinity $\beta_{2}$ integrins or genetic deletion of talin-1 or kindlin-3 was found to enhance neutrophil trafficking with modest impairment of phagocytosis during Pseudomonas aeruginosa-pneumonia in mice (71). Another potential inhibitory signal is the interaction of the $\alpha I-$ domain of Mac-1 in the bent state with the sialylated ectodomain of the IgG receptor Fc $\gamma$ RIIA in cis, leading to reduced Fc $\gamma$ RIIA affinity to IgG and subsequently decreased neutrophil recruitment to immune complexes deposited in the vessel wall (33). Disruption of this interaction may increase neutrophil recruitment in autoimmune diseases.

Neutrophils from myeloperoxidase knockout mice display increased surface expression of Mac-1 and a pro-migratory phenotype in a murine model of ischemia-reperfusion-induced 
TABLE 1 | Selected Mac-1 (CD11b/CD18) ligands and their actions.

\begin{tabular}{|c|c|c|c|c|}
\hline Ligands & Species & Effects & Mechanism & References \\
\hline \multicolumn{5}{|l|}{ Binding site: $\alpha_{M} l$-domain } \\
\hline \multirow[t]{5}{*}{ ICAM-1 } & Human & Mediates neutrophil adhesion and & $\beta_{2}$ integrin conformational changes & $(10,11,29$ \\
\hline & Mouse & transmigration & & 30) \\
\hline & Human & Limits neutrophil adhesion & High affinity bent conformation of $\beta 2$ integrins & $(31-33)$ \\
\hline & Human & $\uparrow$ Neutrophil lifespan & $\uparrow \mathrm{Akt}, \uparrow \mathrm{ERK}$ & $(14,15,34$ \\
\hline & & $\downarrow$ Apoptosis & $\uparrow \mathrm{Mcl}-1$ & 35) \\
\hline \multirow[t]{3}{*}{ Fibrinogen } & Human & Initiates coagulation & & \\
\hline & & $\uparrow$ Neutrophil lifespan & $\uparrow \mathrm{Akt}, \uparrow \mathrm{ERK}$ & $(36)$ \\
\hline & & $\downarrow$ Apoptosis & $\uparrow N F-\kappa B$ & \\
\hline \multirow[t]{3}{*}{ Plasminogen } & Human & Initiates fibrinolysis & & \\
\hline & & $\uparrow$ Neutrophil lifespan & $\uparrow A k t, \uparrow \mathrm{ERK}$ & $(36,37)$ \\
\hline & & $\downarrow$ Apoptosis & $\uparrow N F-\kappa B$ & \\
\hline \multirow[t]{6}{*}{ Myeloperoxidase } & Mouse & $\downarrow$ Neutrophil trafficking & Impaired Mac-1 function & $(38)$ \\
\hline & Mouse & $\uparrow$ Endothelial cell damage & Transfer of Mac-1-bound myeloperoxidase & (39) \\
\hline & Human & $\uparrow$ Neutrophil lifespan & $\uparrow A k t, \uparrow E R K, \uparrow M c l-1$ & $(40)$ \\
\hline & & $\downarrow$ Apoptosis & & \\
\hline & Human & $\uparrow$ Myeloperoxidase and elastase & $\uparrow$ Akt, $\uparrow \mathrm{ERK}$ & $(40,41)$ \\
\hline & Mouse & release & $\uparrow N F-\kappa B$ & \\
\hline \multirow[t]{3}{*}{ Neutrophil elastase } & Human & Reverse transendothelial migration & Elastase-mediated cleavage of JAM-C & $(42)$ \\
\hline & Zebrafish & & & (43) \\
\hline & Mouse & & & $(44-46)$ \\
\hline \multirow[t]{4}{*}{ Proteinase 3} & Human & Auto-antigen & Disrupts immune silencing & $(47-50)$ \\
\hline & & $\downarrow$ Efferocytosis & "Don’t eat me" signal & $(47,51,52)$ \\
\hline & & & (in cooperation with & \\
\hline & & & CD16 and CD177) & \\
\hline \multirow[t]{3}{*}{ LL-37 (Cathelicidin) } & Human & $\uparrow$ Phagocytosis & Opsonizes bacteria & (53) \\
\hline & Human & Auto-antigen & Psoriasis & $(54)$ \\
\hline & Mouse & Auto-antigen & Atherosclerosis (?) & (55) \\
\hline Platelet factor 4 & Human & $\uparrow$ Phagocytosis & Opsonizes bacteria & $(56)$ \\
\hline \multirow[t]{4}{*}{ C3b (C3b-opsonized bacteria) } & Human & $\uparrow$ Phagocytosis & $\uparrow \mathrm{ROS}, \uparrow$ caspase-3 & $(14,57,58)$ \\
\hline & & $\uparrow \mathrm{PICD}$ & $\downarrow \mathrm{Mcl}-1$ & \\
\hline & Mouse & $\uparrow \mathrm{PICD}$ & & $(57,58)$ \\
\hline & & $\uparrow$ Bacterial clearance & & \\
\hline CD40 ligand & Mouse & $\uparrow$ Leukocyte recruitment & Mac- 1 as an alternate receptor for CD40L & (59) \\
\hline & & $\uparrow$ Atherogenesis & (independent of CD40) & \\
\hline \multirow[t]{2}{*}{ Dynorphin A } & Mouse & $\uparrow$ Migration & & (60) \\
\hline & & $\uparrow$ Phagocytosis & & \\
\hline \multicolumn{5}{|l|}{ Binding site: Lectin-like domain } \\
\hline Fungus: & Human & $\uparrow$ NET release & $\downarrow$ or $\uparrow$ ROS, $\uparrow$ Syk, $\uparrow$ PAD4 (fungus species- & $(61-64)$ \\
\hline A. fumigatus, C. albicans & & & dependent) & \\
\hline Immobilized fungal $\beta$-glucan & Human & $\uparrow$ NET release & ROS-independent & $(62,63)$ \\
\hline \multirow{4}{*}{$\begin{array}{l}\text { Binding sites } \alpha_{M} \text {-domain and Lectin-like domain: } \\
\text { C3b-opsonized tumor cells treated with } \beta \text {-glucan }\end{array}$} & & & & \\
\hline & Mouse & $\uparrow$ Tumor cell killing & $\uparrow$ Syk, $\uparrow$ PI3K, & (28) \\
\hline & & & $\uparrow$ Mac- 1 toxicity & \\
\hline & & & Dual Mac-1 ligation & \\
\hline
\end{tabular}

C3b, complement 3b; NET, neutrophil extracellular trap; PAD4, protein-arginine deiminase type 4; PICD, phagocytosis-induced cell death; ROS, reactive oxygen species.

liver damage (38). Hence, myeloperoxidase may impair Mac-1 function and subsequently limit neutrophil trafficking into ischemic tissues. Neutrophil-derived myeloperoxidase was reported to protect mice from endotoxin-induced inflammation and mortality (72), though the involvement of $\beta_{2}$ integrins in these actions remains to be investigated. On the other side, cell contact-dependent, Mac-1-mediated transfer of myeloperoxidase from neutrophils to endothelial cells can disrupt normal endothelial function (39), leading to endothelial inflammation that underlies atherosclerosis and vasculitis. Following neutrophil adhesion to the endothelium, gelatinase granules translocate to the cell surface and externalize the phospholipid-binding protein annexin A1 (73). Annexin A1 promotes the detachment of adhering leukocytes presumably through inhibiting CCL5-induced switch in $\beta_{2}$ integrin conformation, and reducing $\alpha_{4} \beta_{1}$ integrin clustering and activation $(74,75)$. Hence, annexin A1 may function as an endogenous stop signal for neutrophil trafficking (76).

\section{REVERSE TRANSENDOTHELIAL MIGRATION}

In addition to moving from the vascular lumen to the extravascular tissue, neutrophils also exhibit reverse motility through the endothelium, known as reverse transendothelial migration (TEM) both in vitro $(42)$ and in vivo $(44,45)$. This 
neutrophil reverse TEM response is relatively prevalent under conditions of ischemia-reperfusion injury, which is associated with reduced expression of junctional adhesion molecule $\mathrm{C}$ (JAM-C) at endothelial cell junctions $(45,46)$. Pharmacological blockade or genetic deletion of JAM-C enhances the frequency of neutrophil reverse TEM in mouse cremaster venules (45). Under ischemia-reperfusion, locally generated $\mathrm{LTB}_{4}$, likely produced by the neutrophils themselves (68), induces elastase release from neutrophils through the $\mathrm{LTB}_{4}$ receptor BLT1 (44). Activated Mac-1 binds neutrophil elastase (77) and JAM-C (78), thereby acting as a molecular "bridge" to facilitate elastase-mediated cleavage of JAM-C and consequently reverse TEM (44) (Figure 1). The importance of Mac-1-bound elastase is further highlighted by the failure of exogenous neutrophil elastase to cleave JAM-C (44). Reversely migrated neutrophils display a phenotype (ICAM-1 ${ }^{\text {high }}$, CXCR $1^{\text {low }}$ ) distinct from tissue-resident or circulating neutrophils and increased capacity to produce superoxide $(42,45)$. At present, the functional implications of neutrophils undergoing reverse TEM remain unclear. Reverse TEM might facilitate the removal of neutrophils from inflamed tissues, thereby promoting the resolution of inflammation $(43,79)$. Alternatively, re-entry of a small subset of activated neutrophils into the blood circulation could contribute to spreading a local inflammatory response, ultimately leading to distant organ damage $(44,45)$. This notion is supported by the association between the percentage of ICAM- $1^{\text {high }}$ neutrophils and the severity of lung inflammation in the mouse cremaster ischemia-reperfusion model (45).

\section{EXTENDING NEUTROPHIL LIFESPAN AND SUPPRESSION OF APOPTOSIS}

Circulating neutrophils have a short lifespan (80, 81), though some reports estimated that their lifespan to be 5.4 days (82). Neutrophils have increased, albeit variable lifetimes upon activation and in healthy and inflamed tissues (4, 6, 83, 84). Blood neutrophils die by constitutive apoptosis. This cell death program renders neutrophils unresponsive to extracellular stimuli and ensures their timely removal from the inflammatory sites by macrophages via efferocytosis, thereby limiting their potentially harmful actions to the host $(2,85,86)$. Extended neutrophil lifespan through suppressed apoptosis is observed in patients with chronic inflammation, for example, acute coronary syndrome (87), asthma (88) or sepsis (89), and is associated with increased disease severity. Consistently, studies in experimental models documented that delaying neutrophil apoptosis can adversely affect the outcome of inflammation (40, 90, 91).

During transendothelial migration and at sites of inflammation, neutrophils receive pro-survival cues that extend their lifespan by delaying intrinsic apoptosis $(4,85,86)$. Neutrophil adherence to the Mac-1 endothelial counter-ligand ICAM-1induces activation of the PI3k/Akt and MAPK/ERK pathways $(34,35)$, leading to suppression of caspase-3 activity through preserving the anti-apoptotic protein $\mathrm{Mcl}-1$, a key regulator of neutrophil survival (92). Suppression of apoptosis by the Mac-1 ligands fibrinogen and plasminogen also depends on signaling through Akt and ERK as well as activation of NF- $\mathrm{KB}$ (36). Engagement of both Mac-1 subunits with soluble ligands is essential for the generation of pro-survival cues, whereas adhesion per se is not a prerequisite (37). Another ligand for Mac-1 is myeloperoxidase, a granule protein implicated in pathogen killing and inflicting tissue damage (93-96). Myeloperoxidase binding to Mac-1on human neutrophils leads to activation of the PI3K/Akt, p38 MAPK, MAPK/ERK and NF$\kappa \mathrm{B}$ pathways $(40,41)$ and rescues neutrophil from apoptosis $(40)$. Myeloperoxidase upregulates Mac-1 expression and induces myeloperoxidase release from the primary granules $(40,41)$, thereby forming an autocrine/paracrine feed-forward loop to amplify the inflammatory response (40) (Figure 1). Increased plasma myeloperoxidase levels were detected in patients with acute coronary syndromes or sepsis and were associated with disease severity (41). Dissociation of myeloperoxidase into monomers with diminished biological activities may represent a mechanism to limit neutrophil responses to this protein (97).

\section{PHAGOCYTOSIS AND PHAGOCYTOSIS- INDUCED CELL DEATH}

In contrast to Mac-1 ligation-generated survival signals, outsidein signaling through Mac-1 could also generate pro-apoptosis cues. Thus, phagocytosis of complement C3b-opsonized bacteria or necrotic cells accelerates neutrophil apoptosis, also known as phagocytosis-induced cell death (PICD) $(98,99)$. The antibiotic peptide LL-37 and platelet factor 4 were also reported to opsonize bacteria and promote Mac-1-mediated phagocytosis $(53,56)$. Higher levels of Mac-1 expression on neutrophils from female vs. male mice may partly explain an innate sex bias in neutrophil bactericidal killing (100). Phagocytosis is initiated by lateral clustering of Mac-1 (101) and governed by a delicate balance between Mac-1 and the complement C5a receptor (C5aR or CD88) (102, 103). Mac-1-mediated phagocytosis evokes ROS formation through activation of NADPH oxidase, which is thought to mediate bacterial killing in the phagolysosomes (94). ROS, presumably hydroxyl radicals and $\mathrm{H}_{2} \mathrm{O}_{2}$, activate caspase- 8 and caspase-3, thereby countering survival signals generated by ligation of Mac-1and promoting $\operatorname{PICD}(4,14$, 98). Release of the granule enzymes, neutrophil elastase, proteinase 3 and cathepsin G can impair phagocytosis by cleaving $\mathrm{C} 5 \mathrm{aR}$, though their involvement appears to be context-dependent $(57,104)$ (Figure 1). For example, TLR9 activation augments Mac-1 expression and reduces $\mathrm{C} 5 \mathrm{aR}$ expression through inducing the release of neutrophil elastase and proteinase 3, resulting in defective phagocytosis in human neutrophils and prolongation of lung injury in mice (57). Reduced neutrophil C5aR expression is a common finding in patients with sepsis $(105,106)$ and may explain neutrophil unresponsiveness to C5a in sepsis (103). 


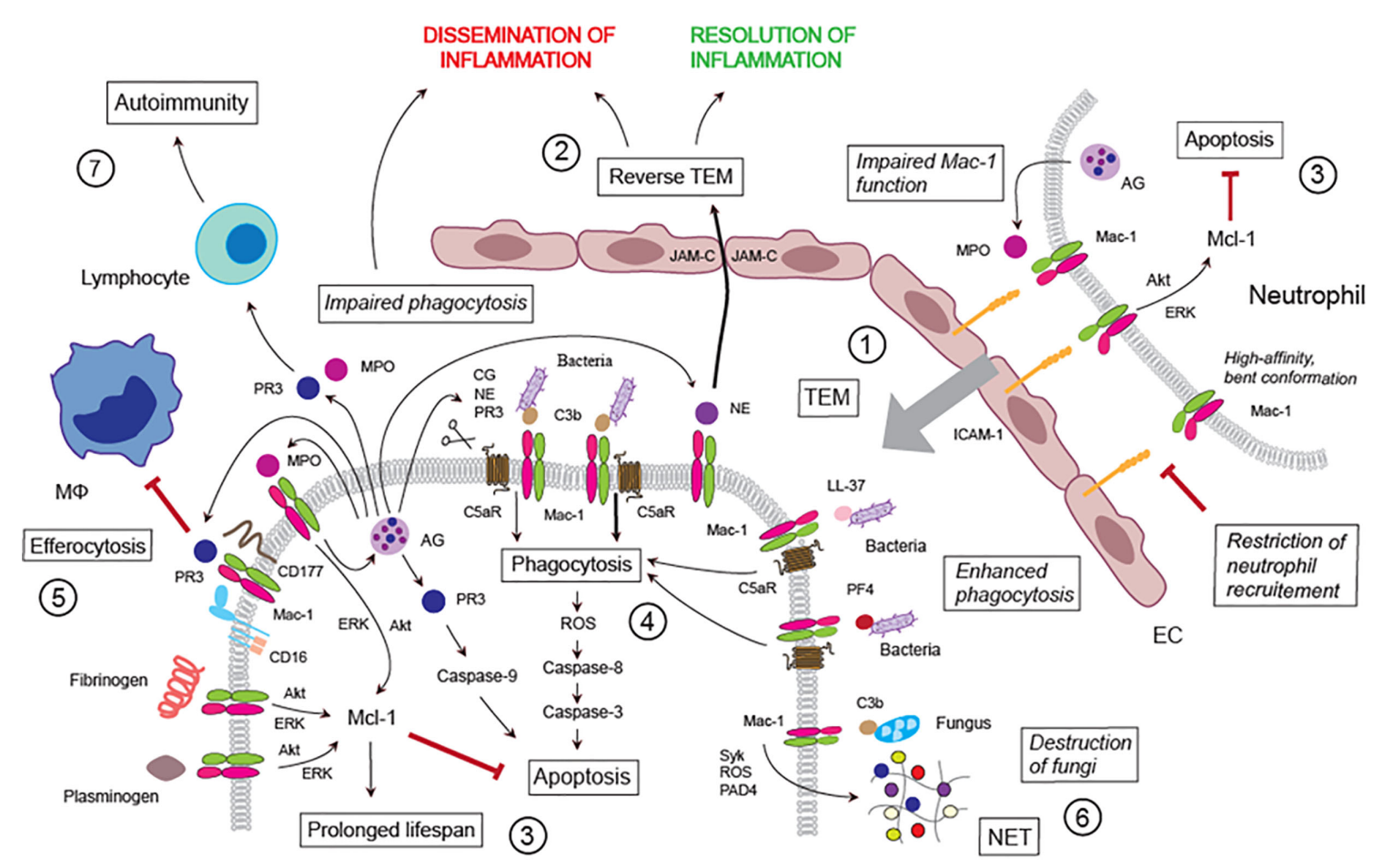

Non-resolving inflammation

Host defense

FIGURE 1 | Mac-1 ligand repertoire shapes host defense and non-resolving inflammation. (1) Transendothelial migration: Mac-1, together with LFA-1, mediates neutrophil adherence to the activated endothelium and transmigration. Conformational changes in Mac-1 (high affinity, bent conformation) and MPO impairment of Mac-1 function may limit neutrophil trafficking. (2) Reverse TEM: Mac-1-bound NE direct neutrophil reverse TEM through binding to and cleaving JAM-C. (3) Neutrophil lifespan: Ligation of Mac-1 with ICAM-1, fibrinogen, plasminogen or MPO generates survival signals for neutrophils through delaying constitutive apoptosis. MPO induces MPO release from the azurophilic granule, thereby forming a feed-forward loop. (4) Phagocytosis: Phagocytosis of complement C3b-opsonized bacteria induces PICD followed by efferocytosis. Cleavage of C5aR (CD88) by NE, PR3 or cathepsin G (released from the azurophilic granule) alters the Mac-1/C5aR ratio, impairs phagocytosis, bacterial clearance and PICD. (5) Inhibition of efferocytosis: PR3 bound to Mac-1(in association with CD16 and CD177) inhibits efferocytosis. (6) NET release: C3b-opsonized fungus or immobilized fungal $\beta$-glucan, which cannot be phagocytosed, evokes release of NET, leading to extracellular killing of the pathogen. (7) Autoimmunity: PR3 and MPO (presented by Mac-1 and/or NET) may induce autoimmunity.

\section{MODULATION OF EFFEROCYTOSIS}

Detection and prompt disposal of apoptotic cells, including neutrophils, generally promote an anti-inflammatory proresolution response at the tissue level and immunological tolerance. The molecular mechanisms include numerous "find$m e$ " and "eat-me" signals that underpin the recognition and subsequent phagocytosis of apoptotic cells by macrophages and dendritic cells (107). Intriguingly, proteinase 3 is expressed on the plasma membrane in association with its partners Mac-1, FcyRIIIb (CD16) and CD177 at a very early stage of apoptosis $(51,108)$ and functions as a "don't eat me" signal that delays uptake of apoptotic neutrophils (52) (Figure 1). Neutrophils lacking CD177, the putative receptor for proteinase 3, express membrane proteinase 3 and respond to proteinase 3-ANCA, suggesting a critical role for Mac-1 and/or FcrRIIIb (47). However, further studies are required to establish how Mac-1 could modulate efferocytosis and contribute to the pathogenesis of ANCA-associated vasculitides. Mac-1 was also reported to support macrophage fusion, leading to the formation of multinucleated giant cells in the inflamed mouse peritoneum (109). The function of these cells remains to be investigated.

\section{INDUCTION OF RAPID NET RELEASE}

Neutrophils can release extracellular traps (NET) to immobilize and kill harmful bacterial, fungal and viral pathogens in the extracellular space when phagocytosis is not feasible (110-112). The classical pathway of NET extrusion involves activation of NADPH oxidase via the Raf-MEK-ERK and p38 MAPK pathways, myeloperoxidase- and elastase-mediated cleavage of histones and protein-arginine deiminase 4 (PAD4)-mediated chromatin decondensation, eventually leading to extrusion of a DNA scaffold studded with citrullinated histones and cytotoxic granular proteins $(113,114)$. A more rapid or "vital" NET release occurs in response to Staphylococcus aureus, 
Candida albicans, Aspergillus fumigatus and Leishmania promastigotes independently of ROS in the presence of matrix and without compromising neutrophil viability $(61,115,116)$ or by selective extrusion of mitochondrial DNA (117). Mac-1 recognition of Candida hyphae, the invasive filamentous forms of $C$. albicans that are too large to be phagocytosed, or immobilized fungal $\beta$-glucan triggers rapid NET release and initiates respiratory burst, which is then suppressed by binding of Mac-1 to the extracellular matrix $(62,63)$ (Figure 1). Mac-1 also triggers NETosis to Aspergillus living conidia through ROS generation downstream to activation of the Src kinase Syk and PI3k- $\delta$, but independently of PAD4 (64). Platelet binding to neutrophils ensuing NET release is mediated either by LFA1 along liver sinusoid in sepsis (118) or Mac-1 along the vascular endothelium during sterile lung injury in mice (119). Hence, it is plausible that the context of NET-inducing stimuli would activate different signaling pathways for NET extrusion. Similar to neutrophil recruitment, a crosstalk between kindlin-3 and $\beta_{2}$ integrins is required for NET release in mice (120). Of note, yeast $\beta$-glucan was reported to enhance killing of $\mathrm{iC} 3 \mathrm{~b}-$ opsonized tumor cells through activation of the Syk-PI3K signaling pathway, indicating dual Mac-1 ligation (28) (Table 1). Whether the cytotoxic action involves NET formation remains to be explored.

\section{AUTOIMMUNITY}

Many neutrophil granule proteins are recognized self-antigens in autoimmunity. Myeloperoxidase and proteinase 3 are target antigens in different forms of anti-neutrophil cytoplasmic antibody (ANCA)-associated vasculitides (48, 49), whereas the antimicrobial protein LL-37 is an autoantigen in psoriasis (54). Externalization of these molecules, together with other well-known antigens, such as double-stranded DNA and histones, through aberrant NET formation has been implicated in triggering a systemic autoimmune response in susceptible individuals (49). Myeloperoxidase might trigger autoimmunity during uncontrolled inflammation in mice (121), though it is unclear whether this involves $\beta_{2}$ integrins and/or NET formation. Proteinase 3 was found to bind directly to Mac-1 (51) or form a complex with the glycosylphosphatidylinositol (GPI)-anchored neutrophil-specific receptor NB1 (CD177) expressed on the surface of a subpopulation of human neutrophils (122) (Figure 1). While surface plasmon resonance analysis indicated direct interaction of NB1 with both LFA1 and Mac-1, only Mac-1 functions as an adaptor for NB1-mediated proteinase 3-ANCA-induced neutrophil activation (123). Proteinase 3 expressed on the surface of apoptotic neutrophils disrupts immune silencing associated with efferocytosis through plasmocytoid dendritic cell-driven generation of Th9/Th2 cells and Th17 response, consistent with promoting systemic necrotizing vasculitis (50). Recent data identified the cathelicidin protein CRAMP (a truncated form of the mouse homolog of hCAP18) as a potential autoantigen in ApoE-deficient mice (55). Although LL-37 was found to bind to Mac-1 (53), the relevance of this interaction to atherosclerosis remains to be investigated.

\section{THERAPEUTIC TARGETING $\beta 2$ INTEGRINS TO PROMOTE RESOLUTION OF INFLAMMATION}

In the light of their functional significance in shaping neutrophil responses, $\beta_{2}$ integrins appear to be attractive therapeutic targets. However, prolonged global blockade of $\beta_{2}$ integrins may have limited usefulness because of the potential of development of LAD-like symptoms. Attractive alternative approaches may be targeting $\beta_{2}$ integrin conformation or ligand-specific signaling circuits by specialized pro-resolving mediators (SPMs) without compromising the ability of neutrophils to contain the microbial invasion.

The currently available drugs (monoclonal antibodies or small molecules) inhibit the ligand-binding site and block a broad repertoire of $\beta_{2}$ integrin functionality (124). Although the beneficial actions of genetic deletion and pharmacological blockade of $\beta_{2}$ integrins have been documented in a number of neutrophil-driven inflammatory models $(6,29,124)$, conventional anti- $\beta_{2}$ integrin blockade lacks specificity and inhibits phagocytosis, promotes apoptosis, and potentiates bacteremia and bacterial sepsis (125). Development of the antiM7 monoclonal antibody that specifically inhibits Mac-1 interaction with its ligand CD40L without interfering with other $\beta_{2}$ integrin ligands $(59,125)$ opens a new avenue for ligand-targeted anti-Mac-1 therapy. An alternative strategy will be developing allosteric inhibitors that stabilize $\beta_{2}$ integrins in the high affinity bent conformation to block neutrophil adherence $(31,71)$ or to prevent the deleterious effects of immune complex-evoked neutrophil accumulation (33). This might be achieved by selectively targeting discrete glycan motifs present on Mac-1 (126). Thus, plant lectins were shown to reduce Mac-1-mediated adhesion, trans-epithelial migration and ROS production, while enhancing phagocytosis and neutrophil apoptosis (126). Intriguingly, the activation of Mac-1 with the small molecule agonists leukadherins was reported to reduce leukocyte trafficking, arterial narrowing and renal dysfunction, while increasing leukocyte adherence to the endothelium in murine models (127). Leukadherin-1 promotes macrophage polarization toward a pro-inflammatory phenotype through activating microRNA Let7a, thereby driving anti-tumor immunity (128).

SPMs include protein and lipid mediators that are mobilized and/or synthesized during the resolution phase of inflammation. For example, annexin A1 is mobilized from the cytoplasm pool to the cell surface and signals through the lipoxin $\mathrm{A}_{4} /$ formyl-peptide receptor 2 (ALX/FPR2) to induce detachment of adhered neutrophils $(74,129)$. The family of lipid SPMs consists of lipoxins, resolvins, protectins and maresins (3, 130, 131). These lipids act through specific receptors and exhibit cellspecific properties, however, their primary targets are 
myeloidcells $(3,132)$. In general, lipid SPMs prevent upregulation of Mac-1 expression and inhibit $\beta_{2}$-integrinmediated neutrophil adhesion, transendothelial migration and consequently tissue accumulation [signaling pathways and networks are mapped into the searchable Atlas of Inflammation Resolution (133)]. For example, lipoxin $\mathrm{A}_{4}$ mobilizes annexin A1 to form an endogenous antiinflammation loop to limit neutrophil trafficking into inflammatory loci (134). Aspirin triggered 15-epi-lipoxin $\mathrm{A}_{4}$, acting through ALX/FPR2, disrupts the myeloperoxidasecentered self-amplifying loop and redirects neutrophil to apoptosis (58), and enhances phagocytosis of bacteria by restoring the balance between $\mathrm{Mac}-1$ and $\mathrm{C} 5 \mathrm{aR}$ expression in human neutrophils (57). Consistently, 15-lipoxin $\mathrm{A}_{4}$ accelerates the resolution of inflammation in mouse models of myeloperoxidase (58) or E. coli-induced acute lung injury (57).

\section{CONCLUSIONS}

Unlike other integrins, the $\beta_{2}$ integrin Mac-1 has two spatially distinct binding sites and exhibits broad ligand recognition specificity and numerous neutrophil responses. A novel aspect of Mac-1 bioactivity is that its conformations and ligands contribute to neutrophil functional plasticity and

\section{REFERENCES}

1. Nauseef WM, Borregaard N. Neutrophils at work. Nat Immunol (2014) 15:602-11. doi: 10.1038/ni.2921

2. Nathan C, Ding A. Nonresolving inflammation. Cell (2010) 140:871-82. doi: 10.1016/j.cell.2010.02.029

3. Serhan CN, Levy BD. Resolvins in inflammation: emergence of the proresolving superfamily of mediators. J Clin Invest (2018) 128:2657-69. doi: 10.1172/JCI97943

4. Filep JG, Ariel A. Neutrophil heterogeneity and fate in inflamed tissues: implications for the resolution of inflammation. Am J Physiol Cell Physiol (2020) 319:C510-32. doi: 10.1152/ajpcell.00181.2020

5. Mantovani A, Cassatella MA, Costantini C, Jaillon S. Neutrophils in the activation and regulation of innate and adaptive immunity. Nat Rev Immunol (2011) 11:519-31. doi: 10.1038/nri3024

6. Liew PX, Kubes P. The neutrophil's role during health and disease. Physiol Rev (2019) 99:1223-48. doi: 10.1152/physrev.00012.2018

7. Jones HR, Robb CT, Perretti M, Rossi AG. The role of neutrophils in inflammation resolution. Semin Immunol (2016) 28:137-45. doi: 10.1016/ j.smim.2016.03.007

8. Potey PMD, Rossi AG, Lucas CD, Dorward DA. Neutrophils in the initiation and resolution of acute pulmonary inflammation: understanding biological function and therapeutic potential. J Pathol (2019) 247:672-85. doi: $10.1002 /$ path.5221

9. Ross GD. Regulation of the adhesion versus cytotoxic functions of Mac-1/ CR3/alphaMbeta2- integrin glycoprotein. Crit Rev Immunol (2000) 20:197222. doi: 10.1615/CritRevImmunol.v20.i3.20

10. Ley K, Laudanna C, Cybulsky MI, Nourshargh S. Getting to the site of inflammation: the leukocyte adhesion cascade updated. Nat Rev Immunol (2007) 7:678-89. doi: 10.1038/nri2156

11. Filippi MD. Neutrophil transendothelial migration: updates and new perspectives. Blood (2019) 133:2149-56. doi: 10.1182/blood-2018-12-844605 heterogeneity. The classical view of $\beta_{2}$ integrins does not accommodate all aspects of their role in neutrophil biology. Their role in regulating neutrophil reverse transmigration, lifespan, phagocytosis-induced cell death, NET formation and efferocytosis extend the $\beta_{2}$ integrin repertoire in shaping innate and adaptive immunity and may partly explain neutrophil heterogeneity. Understanding the functions of $\beta_{2}$ integrins may be instrumental to develop novel therapies specifically targeting pro-resolution actions without compromising immunity.

\section{AUTHOR CONTRIBUTIONS}

MS, AO, and JF conceived, designed, and wrote the manuscript. All authors contributed to the article and approved the submitted version.

\section{FUNDING}

This study was supported by grants from the Canadian Institutes of Health Research (MOP-97742 and MOP-102619) (to JF).

12. Harris ES, Weyrich AS, Zimmerman GA. Lessons from rare maladies: leukocyte adhesion deficiency syndromes. Curr Opin Hematol (2013) 20:16-25. doi: 10.1097/MOH.0b013e32835a0091

13. Fagerholm SC, Gunther C, Llort Asens M, Savinko T, Uotila LM. Beta2integrins and interacting proteins in leukocyte trafficking, immune suppression, and immunodeficiency. Front Immunol (2019) 10:254. doi: 10.3389/fimmu.2019.00254

14. Mayadas TN, Cullere X. Neutrophil $\beta 2$ integrins: moderators of life and death decisions. Trends Immunol (2005) 26:388-95. doi: 10.1016/ j.it.2005.05.002

15. El Kebir D, Filep JG. Modulation of neutrophil apoptosis and the resolution of inflammation through $\beta_{2}$ integrins. Front Immunol (2013) 4:1-5. doi: 10.3389/fimmu.2013.00060

16. Han C, Jin Y, Xu S, Liu H, Li N, Cao X. Integrin CD11b negatively regulates TLR-triggered inflammatory responses by activating Syk and promoting degradation of MyD88 and TRIF via Cbl-b. Nat Immunol (2010) 11:734-42. doi: 10.1038/ni.1908

17. Rosetti F, Mayadas TN. The many faces of Mac-1 in autoimmune disease Immunol Rev (2016) 269:175-93. doi: 10.1111/imr.12373

18. Podolnikova NP, Podolnikov AV, Haas TA, Lishko VK, Ugarova TP. Ligand recognition specificity of leukocyte integrin $\alpha \mathrm{M} \beta 2$ (Mac-1, CD11b/CD18) and its functional consequences. Biochemistry (2015) 54:1408-20. doi: 10.1021/bi5013782

19. Luo BH, Carman CV, Springer TA. Structural basis of integrin regulation and signaling. Annu Rev Immunol (2007) 25:619-47. doi: 10.1146/ annurev.immunol.25.022106.141618

20. Fan Z, Ley K. Leukocyte arrest: biomechanics and molecular mechanisms of $\beta 2$ integrin activation. Biorheology (2015) 52:353-77. doi: 10.3233/BIR15085

21. Alon R, Feigelson SW. Chemokine-triggered leukocyte arrest: forceregulated bi-directional integrin activation in quantal adhesive contacts Curr Opin Cell Biol (2012) 24:670-6. doi: 10.1016/j.ceb.2012.06.001 
22. Kim C, Ye F, Grinsberg MH. Regulation of integrin activation. Annu Rev Cell Dev Biol (2011) 27:321-45. doi: 10.1146/annurev-cellbio-100109-104104

23. El Azreq MA, Garceau V, Bourgoin SG. Cytohesin-1 regulates fMLFmediated activation and functions of the $\beta_{2}$ integrin Mac-1 in human neutrophils. J Leukoc Biol (2011) 89:823-36. doi: 10.1189/j1.0410222

24. Boras M, Volmering S, Bokemeyer A, Rossaint J, Block H, Bardel B, et al. Skap2 is required for $\beta 2$ integrin-mediated neutrophil recruitment and functions. J Exp Med (2017) 214:851-74. doi: 10.1084/jem.20160647

25. Yakubenko VP, Lishko VK, Lam SC-T, Ugarova TP. A molecular basis for integrin alphaMbeta2 ligand binding promiscuity. J Biol Chem (2002) 277:48635-42. doi: 10.1074/jbc.M208877200

26. Feng W, Nguyen H, Shen D, Deng H, Jiang Z, Podolnikova N, et al. Structural characterization of the interaction between the $\alpha \mathrm{MI}$-domain of the integrin Mac-1 $(\alpha \mathrm{M} \beta 2)$ and the cytokine pleiotrophin. Biochemistry (2021) 60:182-93. doi: 10.1021/acs.biochem.0c00700

27. O`Brian XM, Reichner JS. Neutrophil integrins and matrix ligands and NET release. Front Immunol (2016) 7:363:363. doi: 10.3389/fimmu.2016.00363

28. Li B, Allendorf DJ, Hansen R, Marroquin J, Ding C, Cramer DE, et al. Yeast beta-glucan amplifies phagocyte killing of iC3b-opsonized tumor cells via complement receptor 3-Syk-phosphatidylinositol 3-kinase pathway. J Immunol (2006) 177:1661-9. doi: 10.4049/jimmunol.177.3.1661

29. Kolaczkowska E, Kubes P. Neutrophil recruitment and function in health and inflammation. Nat Rev Immunol (2013) 13:159-75. doi: 10.1038/nri3399

30. Nourshargh S, Alon R. Leukocyte migration into inflamed tissues. Immunity (2014) 41:694-707. doi: 10.1016/j.immuni.2014.10.008. 2014.

31. Fan Z, McArdle S, Marki A, Mikulski Z, Gutierrez E, Engelhardt B, et al. Neutrophil recruitment limited by high-affinity bent $\beta 2$ integrin binding ligand in cis. Nat Commun (2016) 7:12658. doi: 10.1038/ncomms12658

32. Fan Z, Kiosses WB, Sun H, Oreicchioni M, Ghosheh Y, Zajonc DM, et al. High-affinity bent $\beta 2$-integrin molecules in arresting neutrophils face each other through binding to ICAMs in cis. Cell Rep (2019) 26:119-30. doi: 10.1016/j.cellrep.2018.12.038

33. Saggu G, Okubo K, Chen Y, Vattepu R, Tsuboi N, Rosetti F, et al. Cis interaction between sialylated FcrRIIA and the $\alpha$ I-domain of Mac-1 limits antibody-mediated neutrophil recruitment. Nat Commun (2018) 9:5058. doi: 10.1038/s41467-018-07506-1

34. Whitlock BB, Gardai S, Fadok V, Bratton D, Henson PM. Differential roles for $\mathrm{a}(\mathrm{M}) \mathrm{b}(2)$ integrin clustering or activation in the control of apoptosis via regulation of Akt and ERK survival mechanisms. J Cell Biol (2000) 151:130520. doi: $10.1083 /$ jcb.151.6.1305

35. Yan SR, Sapru K, Issekutz AC. The CD11/CD18 (beta2) integrins modulate neutrophil caspase activation and survival following TNF-alpha or endotoxin-induced transendothelial migration. Immunol Cell Biol (2004) 82:435-46. doi: 10.1111/j.0818-9641.2004.01268.x

36. Rubel C, Gomez S, Fernandez GC, Isturiz MA, Caamaño J, Palermo MS. Fibrinogen-CD11b/CD18 interaction activates the NF-kB pathway and delays apoptosis in human neutrophils. Eur J Immunol (2003) 33:1429-38. doi: $10.1002 /$ eji.200323512

37. Pluskota E, Soloviev DA, Szpak D, Weber C, Plow EF. Neutrophil apoptosis: selective regulation by different ligands of integrin $\alpha_{M} \beta_{2}$. J Immunol (2008) 181:3609-19. doi: 10.4049/jimmunol.181.5.3609

38. Tseng A, Kim K, Li J, Cho J. Myeloperoxidase negatively regulates neutrophil-endothelial cell interactions by impairing $\alpha \mathrm{M} \beta 2$ integrin function in sterile inflammation. Front Med (Lausanne) (2018) 5:134:134. doi: 10.3389/fmed.2018.00134

39. Jerke U, Rolle S, Purfürst B, Luft FC, Nauseef WM, Kettritz R. $\beta_{2}$ integrinmediated cell-cell contact transfers active myeloperoxidase from neutrophils to endothelial cells. J Biol Chem (2013) 288:12910-9. doi: 10.1074/jbc.M112.434613

40. El Kebir D, József L, Pan W, Filep JG. Myeloperoxidase delays neutrophil apoptosis through CD11b/CD18 integrins and prolongs inflammation. Circ Res (2008) 103:352-9. doi: 10.1161/01.RES.0000326772.76822.7a

41. Lau D, Mollnau H, Eiserich JP, Freeman BA, Daiber A, Gehling UM, et al. Myeloperoxidase mediates neutrophil activation by association with CD11b/ CD18 integrins. Proc Natl Acad Sci USA (2005) 102:431-6. doi: 10.1073/ pnas.0405193102

42. Buckley CD, Ross EA, McGettrick HM, Osborne CE, Haworth O, Schmutz C, et al. Identification of a phenotypically and functionally distinct population of long-lived neutrophils in a model of reverse endothelial migration. J Leukoc Biol (2006) 79:303-11. doi: 10.1189/ jlb.0905496

43. Mathias JR, Perrin BJ, Liu TX, Kanki J, Look AT, Huttenlocher A. Resolution of inflammation by retrograde chemotaxis of neutrophils in transgenic zebrafish. J Leukoc Biol (2006) 80:1281-8. doi: 10.1189/jlb.0506346

44. Colom B, Bodkin JV, Beyrau M, Woodfin A, Ody C, Rourke C, et al. Leukotriene B4-neutrophil elastase axis drives neutrophil reverse transendothelial cell migration in vivo. Immunity (2015) 42:1075-86. doi: 10.1016/j.immuni.2015.05.010

45. Woodfin A, Voisin MB, Beyrau M, Colom B, Caille D, Diapouli FM, et al. The junctional adhesion molecule JAM-C regulates polarized transendothelial migration of neutrophils in vivo. Nat Immunol (2011) 12:761-9. doi: $10.1038 /$ ni.2062

46. Scheiermann C, Colom B, Meda P, Patel NS, Voisin MB, Marrelli A, et al. Junctional adhesion molecule-C mediates leukocyte infiltration in response to ischemia reperfusion injury. Arterioscler Thromb Vasc Biol (2009) 29:1509-15. doi: 10.1161/ATVBAHA.109.187559

47. Witko-Sarsat V, Reuter N, Mouthon L. Interaction of proteinase 3 with its associated partners: implications in the pathogenesis of Wegener's granulomatosis. Curr Opin Rheumatol (2010) 22:1-7. doi: 10.1097/ BOR.0b013e3283331594

48. Jennette JC, Xiao H, Falk RJ. Pathogenesis of vascular inflammation by antineutrophil cytoplasmic antibodies. J Am Soc Nephrol (2006) 17:1235-42. doi: 10.1681/ASN.2005101048

49. Gupta S, Kaplan MJ. The role of neutrophil NETosis in autoimmune and renal diseases. Nat Rev Nephrol (2016) 12:402-13. doi: 10.1038/ nrneph.2016.71

50. Millet A, Martin KR, Bonnefoy F, Saas P, Mocek J, Alkan M, et al. Proteinase 3 on apoptotic cells disrupts immune silencing in autoimmune vasculitis. J Clin Invest (2015) 125:4107-21. doi: 10.1172/JCI78182

51. David A, Kacher Y, Specks U, Aviram I. Interaction of proteinase 3 with CD11b/CD18 (beta2 integrin) on the cell membrane of human neutrophils. J Leukoc Biol (2003) 74:551-7:doi: 10.1189/jlb.1202624. doi: 10.1189/ jlb.1202624

52. Kantari C, Pederzoli-Ribeil M, Amir-Moazami O, Gausson-Dorey V, Moura IC, Lecomte MC, et al. Proteinase 3, the Wegener autoantigen, is externalized during neutrophil apoptosis: evidence for a functional association with phospholipid scramblase 1 and interference with macrophage phagocytosis. Blood (2007) 110:4086-95. doi: 10.1182/blood2007-03-080457

53. Lishko VK, Moreno B, Podolnikova NP, Ugarova TP. Identification of human cathelicidin peptide LL-37 as a ligand for macrophage integrin $\alpha_{M} \beta_{2}$ (Mac-1, CD11b/CD18) that promotes phagocytosis by opsonizing bacteria. Res Rep Biochem (2016) 2016:39-55. doi: 10.2147/rrbc.s107070

54. Morizane S, Gallo RL. Antimicrobial peptides in the pathogenesis of psoriasis. J Dermatol (2012) 39:225-30. doi: 10.1111/j.13468138.2011.01483.x

55. Mihailovic PM, Lio WM, Yano J, Zhao X, Zhou J, Chyu KY, et al. The cathelicidin protein CRAMP is a potential atherosclerosis self-antigen in ApoE(-/-) mice. Plos One (2017) 12:e0187432. doi: 10.371/ journal.pone.0187432

56. Lishko VK, Yakubenko VP, Ugarova TP, Podolnikova NP. Leukocyte integrin Mac-1 (CD11b/CD18, $\left.\alpha_{M} \beta_{2}, C R 3\right)$ acts as a functional receptor for platelet factor 4. J Biol Chem (2018) 293:6869-82. doi: 10.1074/ jbc.RA117.000515

57. Sekheri M, El Kebir D, Edner N, Filep JG. 15-Epi-LXA 4 and 17-epi-RvD1 restore TLR9-mediated impaired neutrophil phagocytosis and accelerate resolution of lung inflammation. Proc Natl Acad Sci USA (2020) 117:797180. doi: 10.1073/pnas.1920193117

58. El Kebir D, József L, Pan W, Wang L, Petasis NA, Serhan CN, et al. 15-epilipoxin $\mathrm{A}_{4}$ inhibits myeloperoxidase signaling and enhances resolution of acute lung injury. Am J Respir Crit Care Med (2009) 180:311-9. doi: 10.1164/ rccm.200810-16010C

59. Wolf D, Hohmann J-D, Wiedermann A, Bledzka K, Blankenbach H, Marchini T, et al. Binding of CD40L to Mac-l's I-domain involves the EQLKKSKTL motif and mediates leukocyte recruitment and atherosclerosis-but does not affect immunity and thrombosis in mice. Circ Res (2011) 109:1269-79. doi: 10.1161/CIRCRESAHA.111.247684 
60. Podolnikova NP, Brothwell JA, Ugarova TP. The opioid peptide dynorphin A induces leukocyte responses via integrin Mac-1 ( $\left.\alpha_{\mathrm{M}} \beta_{2}, \mathrm{CD} 1 \mathrm{~b} / \mathrm{CD} 18\right)$. Mol Pain (2015) 11:33. doi: 10.1186/s12990-015-0027-0

61. Byrd AS, O'Brien XM, Johnson CM, Lavigne LM, Reichner JS. An extracellular matrix-based mechanism of rapid neutrophil extracellular trap formation in response to Candida albicans. J Immunol (2013) 190:4136-48. doi: 10.4049/jimmunol.1202671

62. Lavigne LM, O’Brien XM, Kim M, Janowski JW, Albina JE, Reichner JS. Integrin engagement mediates the human polymorphonuclear leukocyte response to a fungal pathogen-associated molecular pattern. J Immunol (2007) 178:7276-82. doi: 10.4049/jimmunol.178.11.7276

63. O'Brien XM, Reichner JS. Neutrophil integrins and matrix ligands and NET release. Front Immunol (2016) 7:363:363. doi: 10.3389/fimmu.2016.00363

64. Silva JC, Rodrigues NC, Thompson-Souza GA, de S Muniz V, Neves JS, Figueiredo RT. Mac-1 triggers neutrophil DNA extracellular trap formation to Aspergillus fumigatus independently of PAD4 histone citrullination. J Leukoc Biol (2020) 107:69-83. doi: 10.1002/JLB.4A0119-009RR

65. Maas SL, Soehnlein O, Viola JR. Organ-specific mechanisms of transendothelial neutrophil migration in the lung, liver, kidney, and aorta. Front Immunol (2018) 9:2739:2739. doi: 10.3389/fimmu.2018.02739

66. Ostermann G, Weber KS, Zernecke A, Schroder A, Weber C. JAM-1 is a ligand of the $\beta_{2}$ integrin LFA-1 involved in transendothelial migration of leukocytes. Nat Immunol (2002) 3:151-8. doi: 10.1038/ni755

67. Filippi MD, Harris CE, Meller J, Gu Y, Zheng Y, Williams DA. Localization of Rac2 via the $\mathrm{C}$ terminus and aspartic acid 150 specifies superoxide generation, actin polarity and chemotaxis in neutrophils. Nat Immunol (2004) 5:744-51. doi: 10.1038/ni1081

68. Lämmermann T, Afonso PV, Angermann BR, Wang JM, Kastenmüller W, Parent CA, et al. Neutrophil swarms require LTB4 and integrins at sites of cell death in vivo. Nature (2013) 498:371-5. doi: 10.1038/nature12175. 2013.

69. Li N, Yang H, Wang M, Lü S, Zhang Y, Long M. Ligand-specific forces of LFA-1 and Mac-1 in neutrophil adhesion and crawling. Mol Biol Cell (2018) 29:408-18. doi: 10.1091/mbc.E16-12-0827

70. Buffone A, Anderson NR, Hammer DA. Human neutrophils will crawl upstream on ICAM-1 if Mac-1 is blocked. Biophys J (2019) 117:1393-404. doi: 10.1016/j.bpj.2019.08.044

71. Wilson ZS, Ahn LB, Serratelli WS, Belley MD, Lomas-Nera J, Sen M, et al. Activated $\beta 2$ integrins restrict neutrophil recruitment during murine acute Pseudomonal pneumonia. Am J Respir Cell Mol Biol (2017) 56:620-7. doi: 10.1165/rcmb.2016-0215OC

72. Reber LL, Gillis CM, Starkl P, Jönsson F, Sibilano R, Marichal T, et al. Neutrophil myeloperoxidase diminishes the toxic effects and mortality induced by lipopolysaccharide. J Exp Med (2017) 214:1249-58. doi: $10.1084 /$ jem. 20161238

73. Perretti M, Christian H, Wheller SK, Aiello I, Mugridge KG, Morris JF, et al. Annexin 1 is stored within gelatinase granules of human neutrophil and mobilized on the cell surface upon adhesion but not phagocytosis. Cell Biol Int (2000) 24:163-74. doi: 10.1006/cbir.1999.0468

74. Perretti M, D'Acquisto F. Annexin A1 and glucocorticoids as effectors of the resolution of inflammation. Nat Rev Immunol (2009) 9:62-70. doi: 10.1038/nri2470

75. Drechsler M, de Jong R, Roissant J, Viola JR, Leoni G, Wang JM, et al. Annexin A1 counteracts chemokine-induced arterial myeloid cell recruitment. Circ Res (2015) 116:827-35. doi: 10.1161/CIRCRESAHA.116.305825

76. Chatterjee BE, Yona S, Rosignoli G, Young RE, Nourshargh S, Flower RJ, et al. Annexin 1-deficient neutrophils exhibit enhanced transmigration in vivo and increased responsiveness in vitro. J Leukoc Biol (2005) 78:639-46. doi: $10.1189 / \mathrm{jlb} .0405206$

77. Cai TQ, Wright SD. Human leukocyte elastase is an endogenous ligand for the integrin CR3 (CD11b/CD18, Mac-1, alpha M beta 2) and modulates polymorphonuclear leukocyte adhesion. J Exp Med (1996) 184:1213-23. doi: $10.1084 /$ jem.184.4.1213

78. Santoso S, Sachs UJ, Kroll H, Linder M, Ruf A, Preissner KT, et al. The junctional adhesion molecule 3 (JAM-3) on human platelets is a counterreceptor for the leukocyte integrin Mac-1. J Exp Med (2002) 196:679-91. doi: 10.1084/jem.20020267

79. Nourshargh S, Renshaw SA, Imhof BA. Reverse migration of neutrophils: Where, when, how and why? Trends Immunol (2016) 37:273-86. doi: 10.1016/j.it.2016.03.006
80. Lahoz-Beneytez J, Elemans M, Zhang Y, Ahmed R, Salam A, Block M, et al. Human neutrophil kinetics: modeling of stable isotope labeling data supports short blood neutrophil half-lives. Blood (2016) 127:3431-8. doi: 10.1182/blood-2016-03-700336

81. Tak T, Tesselaar K, Pillay J, Borghans JA, Koenderman L. What's your age again? Determination Hum neutrophil half-lives revisited J Leukoc Biol (2013) 94:595-601. doi: 10.1189/jlb.1112571

82. Pillay J, den Braber I, Vrisekoop N, Kwast LM, de Boer RJ, Borghans JA, et al. In vivo labeling with ${ }^{2} \mathrm{H}_{2} \mathrm{O}$ reveals a human neutrophil lifespan of 5.4 days. Blood (2010) 116:625-7. doi: 10.1182/blood-2010-01-259028

83. Ballesteros I, Rubio-Ponce A, Genua M, Lusito E, Kwok I, Fernández-Calvo G, et al. Co-option of neutrophil fates by tissue environments. Cell (2020) 183:1282-97.e18. doi: 10.1016/j.cell.2020.10.003

84. Pfirschke C, Engblom C, Gungabeesoon J, Lin Y, Rickelt S, Zilionis R, et al. Tumor-promoting $\mathrm{Ly}-6 \mathrm{G}^{+}$Siglec $\mathrm{F}^{\text {high }}$ cells are mature and long-lived neutrophils. Cell Rep (2020) 32:108164. doi: 10.1016/j.celrep.2020.108164

85. Savill J, Dransfield I, Gregory C, Haslett C. A blast from the past: clearance of apoptotic cells regulates immune responses. Nat Rev Immunol (2002) 2:96575. doi: 10.1038/nri957. 2002.

86. Gilroy DW, Lawrence T, Perretti M, Rossi AG. Inflammatory resolution: new opportunities for drug discovery. Nat Rev Drug Discovery (2004) 3:40116. doi: $10.1038 / \mathrm{nrd} 1383$

87. Garlichs CD, Eskafi S, Cicha I, Schmeisser A, Walzog B, Raaz D, et al. Delay of neutrophil apoptosis in acute coronary syndromes. J Leukoc Biol (2004) 75:828-35. doi: 10.1189/jlb.0703358

88. Uddin M, Nong G, Ward J, Seumois G, Prince LR, Wilson SJ, et al. Prosurvival activity for airway neutrophils in severe asthma. Thorax (2010) 65:684-9. doi: 10.1136/thx.2009.120741

89. Keel M, Ungethum U, Steckholzer U, Niederer E, Hartung T, Trentz O, et al. Interleukin-10 counterregulates proinflammatory cytokine-induced inhibition of neutrophil apoptosis during severe sepsis. Blood (1997) 90:3356-63. doi: 10.1182/blood.V90.9.3356

90. Jonsson H, Allen P, Peng SL. Inflammatory arthritis requires Foxo3a to prevent Fas ligand-induced neutrophil apoptosis. Nat Med (2005) 11:66671. doi: $10.1038 / \mathrm{nm} 1248$

91. Rossi AG, Sawatzky DA, Walker A, Ward C, Sheldrake TA, Riley NA, et al. Cyclin-dependent kinase inhibitors enhance the resolution of inflammation by promoting inflammatory cell apoptosis. Nat Med (2006) 12:1056-64 doi: $10.1038 / \mathrm{nm} 1468$

92. Dzhagalov I, St. John A, He YW. The antiapoptotic protein Mcl-1 is essential for the survival of neutrophils but not macrophages. Blood (2007) 109:16206. doi: 10.1182/blood-2006-03-013771

93. Klebanoff SJ. Myeloperoxidase: friend or foe. J Leukoc Biol (2005) 77:598625. doi: $10.1189 / \mathrm{jlb} .1204697$

94. Nauseef WM. How human neutrophils kill and degrade microbes: an integrated view. Immunol Rev (2007) 219:88-102. doi: 10.1111/j.1600065X.2007.00550.x

95. Winterbourn CC. Reconciling the chemistry and biology of reactive oxygen species. Nat Chem Biol (2008) 4:278-86. doi: 10.1038/nchembio.85

96. Arnhold J, Flemmig J. Human myeloperoxidase in innate and acquired immunity. Arch Biochem Biophys (2010) 500:92-106. doi: 10.1016/ j.abb.2010.04.008

97. Gorudko IV, Grigorieva DV, Sokolov AV, Shamova EV, Kostevich VA, Kudryavtsev IV, et al. Neutrophil activation in response to monomeric myeloperoxidase. Biochem Cell Biol (2018) 96:592-601. doi: 10.1139/bcb-2017-0290

98. Perskvist N, Long M, Stendahl O, Zheng L. Mycobacterium tuberculosis promotes apoptosis in human neutrophils by activating caspase- 3 and altering expression of $\mathrm{Bax} / \mathrm{Bcl}-\mathrm{xL}$ via an oxygen-dependent pathway. J Immunol (2002) 168:6358-65. doi: 10.4049/jimmunol.168.12.6358

99. De Leo FR. Modulation of phagocyte apoptosis by bacterial pathogens. Apoptosis (2004) 9:399-413. doi: 10.1023/B:APPT.0000031448.64969.fa

100. Pokhrel S, Triplett KD, Daly SM, Joyner JA, Sharma G, Hathaway HJ, et al. Complement receptor 3 contributes to the sexual dimorphism in neutrophil killing of Staphylococcus aureus. J Immunol (2020) 205:1593-600. doi: 10.4049/jimmunol.2000545

101. Freeman SA, Goyette J, Furuya W, Woods EC, Bertozzi CR, Bergmeier W, et al. Integrins form an expanding diffusion barrier that coordinates phagocytosis. Cell (2016) 164:128-40. doi: 10.1016/j.cell.2015.11.048 
102. Mollnes TE, Brekke OL, Fung M, Fure H, Christiansen D, Bergseth G, et al. Essential role of the C5a receptor in E coli-induced oxidative burst and phagocytosis revealed by a novel lepirudin-based human whole blood model of inflammation. Blood (2002) 100:1869-77.

103. Guo RF, Ward PA. Role of C5a in inflammatory responses. Annu Rev Immunol (2005) 23:821-52. doi: 10.1146/annurev.immunol.23.021704.115835

104. Van den Berg CW, Tambourgi DV, Clark HW, Hoong SJ, Spiller OB, McGreal EP. Mechanism of neutrophil dysfunction: Neutrophil serine proteases cleave and inactivate the C5a receptor. J Immunol (2014) 192:1787-95. doi: 10.4049/jimmunol.1301920

105. Conway Morris A, Kefala K, Wilkinson TS, Dhaliwal K, Farrell L, Walsh T, et al. C5a mediates peripheral blood neutrophil dysfunction in critically ill patients. Am J Respir Crit Care Med (2009) 180:19-28. doi: 10.1164/ rccm.200812-1928OC

106. Unnewehr H, Rittirsch D, Sarma JV, Zetoune F, Flierl MA, Perl M, et al. Changes and regulation of the C5a receptor on neutrophils during septic shock in humans. J Immunol (2013) 190:4215-25. doi: 10.4049/ jimmunol.1200534

107. Poon IKH, Lucas CD, Rossi AG, Ravichandran KS. Apoptotic cell clearance: basic biology and therapeutic potential. Nat Rev Immunol (2014) 14:166-80. doi: $10.1038 /$ nri3607

108. Durant S, Pederzoli M, Lepelletier Y, Canteloup S, Nusbaum P, Lesavre P, et al. Apoptosis-induced proteinase 3 membrane expression is independent from degranulation. J Leukoc Biol (2004) 75:87-98. doi: 10.1189/jlb.0203079

109. Podolnikova NP, Kushchayeva YS, Wu Y, Faust J, Ugarova TP. The Role of integrins $\alpha \mathrm{M} \beta 2$ (Mac-1, CD11b/CD18) and $\alpha \mathrm{D} \beta 2(\mathrm{CD} 11 \mathrm{~d} / \mathrm{CD} 18)$ in macrophage fusion. Am J Pathol (2016) 186:2105-16. doi: 10.1016/ j.ajpath.2016.04.001

110. Brinkmann V, Reichard U, Goosmann C, Fauler B, Uhlemann Y, Weiss DS, et al. Neutrophil extracellular traps kill bacteria. Science (2004) 303:1532-5. doi: 10.1126/science. 1092385

111. Bardoel BW, Kenny EF, Sollberger G, Zychlinsky A. The balancing act of neutrophils. Cell Host Microbe (2014) 15:526-36. doi: 10.1016/ j.chom.2014.04.011

112. Urban CF, Reichard U, Brinkmann V, Zychlinsky A. Neutrophil extracellular traps capture and kill Candida albicans yeast and hyphal forms. Cell Microbiol (2006) 8:668-76. doi: 10.1111/j.1462-5822.2005.00659

113. Fuchs TA, Abed U, Goosmann C, Hurwitz R, Schulze I, Wahn V, et al. Novel cell death program leads to neutrophil extracellular traps. J Cell Biol (2007) 176:231-41. doi: 10.1083/jcb.200606027

114. Tessarz P, Kouzarides T. Histone core modifications regulating nucleosome structure and dynamics. Nat Rev Mol Cell Biol (2014) 15:703-8. doi: 10.1038/ nrm3890

115. Pilsczek FH, Salina D, Poon KKH, Fahey C, Yipp BG, Sibley CD, et al. A novel mechanism of rapid nuclear neutrophil extracellular trap formation in response to Staphylococcus aureus. J Immunol (2010) 185:7413-25. doi: 10.4049/jimmunol.1000675

116. Rochael NC, Guimarães-Costa AB, Nascimento MTC, De Souza-Vieira TS, Oliveira MP, Garcia Souza LF, et al. Classical ROS-dependent and early/ rapid ROS-independent release of neutrophil extracellular traps triggered by Leishmania parasites. Sci Rep (2015) 5:18302doi: 10.1038/srep18302. doi: $10.1038 /$ srep 18302

117. Yousefi S, Mihalache C, Kozlowski E, Schmid I, Simon HU. Viable neutrophils release mitochondrial DNA to form neutrophil extracellular traps. Cell Death Differ (2009) 16:1438-44. doi: 10.1038/cdd.2009.96

118. McDonald B, Urrutia R, Yipp BG, Jenne CN, Kubes P. Intravascular neutrophil extracellular traps capture bacteria from the bloodstream during sepsis. Cell Host Microbe (2012) 12:324-33. doi: 10.1016/ j.chom.2012.06.011

119. Rossaint J, Herter JM, Van Aken H, Napirei M, Döring Y, Weber C, et al. Synchronized integrin engagement and chemokine activation is crucial in neutrophil extracellular trap-mediated sterile inflammation. Blood (2014) 123:2573-84. doi: 10.1182/blood-2013-07-516484
120. Xu Z, Cai J, Gao J, White GC2, Chen F, Ma YQ. Interaction of kindlin-3 and $\beta 2$-integrins differentially regulates neutrophil recruitment and NET release in mice. Blood (2015) 126:373-7. doi: 10.1182/blood-2015-03-636720

121. Xiao H, Heeringa P, Hu P, Liu Z, Zhao M, Aratani Y, et al. Antineutrophil cytoplasmic autoantibodies specific for myeloperoxidase cause glomerulonephritis and vasculitis in mice. J Clin Invest (2002) 110:955-63. doi: $10.1172 / J C I 15918$

122. Jerke U, Mariono SF, Daumke O, Kettritz R. Characterization of the CD177 interaction with the ANCA antigen proteinase 3. Sci Rep (2017) 7:43328. doi: $10.1038 /$ srep43328

123. Jerke U, Rolle S, Dittmar G, Bayat B, Santoso S, Sporbert A, et al. Complement receptor Mac-1 is an adaptor for NB1 (CD177)-mediated PR3-ANCA neutrophil activation. J Biol Chem (2011) 286:7070-81. doi: $10.1074 /$ jbc.M110.171256

124. Ley K, Rivera-Nieves J, Sandborn WJ, Shattil S. Integrin-based therapeutics: biological basis, clinical use and new drugs. Nat Rev Drug Discovery (2016) 15:173-83. doi: 10.1038/nrd.2015.10

125. Wolf D, Anto-Michel N, Blankenbach $\mathrm{H}$, Wiedermann A, Buscher K, Hohmann JD, et al. A ligand-specific blockade of the integrin Mac-1 selectively targets pathologic inflammation while maintaining protective host-defense. Nat Commun (2018) 9:525. doi: 10.1038/s41467-018-02896-8

126. Kelm M, Lehoux S, Azcutia V, Cummings RD, Nusrat A, Parkos CA, et al. Regulationof neutrophil function by selective targeting of glycan epitopes expressed on the integrin CD11b/CD18. FASEB J (2020) 34:2326-43. doi: 10.1096/fj.201902542R

127. Maiguel D, Faridi MH, Wei C, Kuwano Y, Balla KM, Hernandez D, et al. Small molecule-mediated activation of the integrin $\mathrm{CD} 11 \mathrm{~b} / \mathrm{CD} 18$ reduces inflammatory disease. Sci Signal (2011) 4:ra57. doi:10.1126/scisignal.2001811 (2001)(

128. Schmid MC, Khan SQ, Kaneda MM, Pathria P, Shephard R, Louis TL, et al. Integrin CD11b activation drives anti-tumor innate immunity. Nat Commun (2018) 9:5379. doi: 10.1038/s41467-018-07387-4

129. Perretti M, Chiang N, La M, Fierro IM, Marullo S, Getting SJ, et al. Endogenous lipid- and peptide-derived anti-inflammatory pathways generated with glucocorticoid and aspirin treatment activate the lipoxin $\mathrm{A}_{4}$ receptor. Nat Med (2002) 8:1296-302. doi: 10.1038/nm786

130. Serhan CN. Pro-resolving lipid mediators are leads for resolution physiology. Nature (2014) 510:92-101. doi: 10.1038/nature13479

131. Serhan CN. Treating inflammation and infection in the 21 st century: new hints for decoding resolution mediators and mechanisms. FASEB J (2017) 31:1273-88. doi: 10.1096/fj.201601222R

132. Chiang N, Serhan CN. Structural elucidation and physiologic functions of specialized pro-resolving mediators and their receptors. Mol Aspects Med (2017) 58:114-29. doi: 10.1016/j.mam.2017.03.005

133. Serhan CN, Gupta SK, Perretti M, Godson C, Brennan E, Li Y, et al. The Atlas of Inflammation Resolution (AIR). Mol Aspects Med (2020) 74:100894. doi: 10.1016/j.mam.2020.100894

134. Brancaleone V, Dalli J, Bena S, Flower RJ, Cirino G, Perretti M. Evidence for an antiinflammatory loop centered on polymorphonuclear leukocyte formyl peptide receptor 2/lipoxin A4 receptor and operative in the inflamed microvasculature. $J$ Immunol (2011) 186:4905-14. doi: 10.4049/jimmunol.1003145

Conflict of Interest: The authors declare that the research was conducted in the absence of any commercial or financial relationships that could be construed as a potential conflict of interest.

Copyright (c) 2021 Sekheri, Othman and Filep. This is an open-access article distributed under the terms of the Creative Commons Attribution License (CC BY). The use, distribution or reproduction in other forums is permitted, provided the original author(s) and the copyright owner(s) are credited and that the original publication in this journal is cited, in accordance with accepted academic practice. No use, distribution or reproduction is permitted which does not comply with these terms. 